\title{
Stereoselective formation of a K-region dihydrodiol from phenanthrene by Streptomyces flavovirens
}

\author{
John B. Sutherland, James P. Freeman, Allison L. Selby, Peter P. Fu, Dwight W. Miller, and Carl E. Cerniglia \\ National Center for Toxicological Research, Food and Drug Administration, Jefferson, AR 72079, USA \\ Received November 24, 1989/Accepted March 21, 1990
}

\begin{abstract}
The metabolism of phenanthrene, a polycyclic aromatic hydrocarbon (PAH), by Streptomyces flavovirens was investigated. When grown for $72 \mathrm{~h}$ in tryptone yeast extract broth saturated with phenanthrene, the actinomycete oxidized $21.3 \%$ of the hydrocarbon at the $\mathrm{K}$-region to form trans-9,10-dihydroxy9,10-dihydrophenanthrene (phenanthrene trans-9,10dihydrodiol). A trace of 9-phenanthrol was also delected. Metabolites isolated by thin-layer and high performance liquid chromatography were identified by comparing chromatographic, mass spectral, and nuclear magnetic resonance properties with those of authentic compounds. Experiments using $\left[9-{ }^{14} \mathrm{C}\right]$ phenanthrene showed that the trans-9,10-dihydrodiol had $62.8 \%$ of the radioactivity found in the metabolites. Circular dichroism spectra of the phenanthrene trans-9,10-dihydrodiol indicated that the absolute configuration of the predominant enantiomer was (-)-9S,10S, the same as that of the principal enantiomer produced by mammalian enzymes. Incubation of $S$. flavovirens with phenanthrene is an atmosphere of ${ }^{18} \mathrm{O}_{2}$, followed by gas chromatographic/mass spectral analysis of the metabolites, indicated that one atom from molecular oxygen was incorporated into each molecule of the phenanthrene trans-9,10-dihydrodiol. Cytochrome P-450 was detected in $105,000 \times g$ supernatants prepared from cell extracts of S.flavovirens. The results show that the oxidation of phenanthrene by $S$. flavovirens was both regio- and stereospecific.
\end{abstract}

Key words: Actinomycetes - Cytochrome P-450 - Dihydrodiol - K-region - Metabolism - Phenanthrene - Polycyclic aromatic hydrocarbons - Streptomyces flavovirens

Offprint requests to: C. E. Cerniglia

Abbreviatiuns: CD, circular dichroism; DMF, $N, N$-dimethylformamide, GC/MS, gas chromatography/mass spectronetry; HPLC, high performance liquid chromatography; NMR, nuclear magnetic resonance; ODS, octadecylsilane; $\mathrm{PAH}$, polycyclic aromatic hydrocarbon; TLC, thin-layer chromatography; TMS, tetramethylsilane; UV, ultraviolet
Phenanthrene, a polycyclic aromatic hydrocarbon (PAH) with three condensed rings, is distributed widely in the environment by anthropogenic processes such as the burning of wood and fossil fuels (Heitkamp and Cerniglia 1987; Guerin 1989; Shiaris 1989). Although phenanthrene is considered relatively nontoxic to mammals (Yoshikawa et al. 1985), it significantly reduces photosynthesis in green algae (Kusk 1981) and is extremely toxic to young rainbow trout (Black et al. 1983). Phenanthrene damages Iysosomal membranes in the digestive cells of marine snails and causes digestive cell deletion in marine mussels (Pipe and Moore 1986a, b). It also decreases reproduction and increases mortality in crustaceans (Savino and Tanabe 1989). Phenanthrene itself is not known to be mutagenic or carcinogenic; however, Bücker et al. (1979) reported the K-region metabolites phenanthrene 9,10-oxide, 9-phenanthrol, and racemic phenanthrene trans-9,10-dihydrodiol to be weakly mutagenic.

Several bacteria are known to catabolize phenanthrene by metabolic pathways that proceed via either catechol or protocatechuic acid (Cerniglia 1984; Gibson and Subramanian 1984; Cerniglia and Heitkamp 1989). Tausson (1928) first reported the isolation from oil-polluted soils of Gram-negative bacteria that assimilate phenanthrene. Pseudomonas and Flavobacterium strains oxidize phenanthrene to phenanthrene 3,4-dihydrodiol, 3,4-dihydroxyphenanthrene, 1-hydroxy-2-naphthaldehyde, 1-hydroxy-2-naphthoic acid, and 1,2-dihydroxynaphthalene (Rogoff and Wender 1957; Colla et al. 1959; Evans et al. 1965). Further catabolism of 1,2-dihydroxynaphthalene by the Pseudomonas sp. appears to be by the naphthalene pathway (Evans et al. 1965). The 3,4dihydrodiol produced from phenanthrene by Beijerinckia sp. and Pseudomonas putida has been shown conclusively to be the cis stercoisomer (Jerina et al. 1976), Beijerinckia $\mathrm{sp}$. also produces a small amount of the cis stereoisomer of the 1,2-dihydrodiol (Jerina et al. 1976). Aeromonas sp. and several other bacteria also catabolize phenanthrene through 1-hydroxy-2-naphtboic acid but metabolize it further via 2-carboxybenzaldehyde, $o$-phthalic acid, and protocatechuic acid (Kyohara et al. 1976; Cerniglia 1984; Cerniglia and Heitkamp 1989). 
Among the PAHs, only naphthalene and biphenyl (Smith and Rosazza 1974; Trower et al. 1988) have been shown to be metabolized by streptomycetes. Streptomyces flavovirens, which we selceted after screening several isolates with phenanthrene, has been shown to break down lignocellulose-containing cell walls in tobacco roots (Grossbard 1971) and Douglas-fir phloem (Crawford and Sutherland 1979; Sutherland et al. 1979). This species has also been reported to be an important nitrate reducer in some aquatic ecosystems (Mansour and Shady 1984). Although the strain we used does not have catabolic plasmids, it can accept plasmids from other streptomycetes during growth in soil (Rafii and Crawford 1988).

In this paper, we present data on the metabolism of phenanthrene by S. flavovirens. The principal metabolites are identified and the regio- and stereospecificity of the phenanthrene-metabolizing enzymes are demonstrated.

\section{Materials and methods}

\section{Microorganism and growth conditions}

Streptomyces flavovirens strain no. 28 (Suthcrland et al. 1979) was maintained on slants of tryptone ycast extract agar consisting of $3.0 \mathrm{~g}$ of Bacto-Tryptone (Difco Laboratories, Detroit, MI, USA), $3.0 \mathrm{~g}$ of Bacto-Ycast Extract (Difco), $1.3 \mathrm{~g}$ of $\mathrm{K}_{2} \mathrm{HPO}_{4} \cdot 3 \mathrm{H}_{2} \mathrm{O}$, and $15 \mathrm{~g}$ of Bacto-Agar (Difeo) per liter of distilled water. The $\mathrm{pH}$ was adjusted to 7.4 before sterilization.

Broth cultures were grown in tryptone yeast extract broth containing $50 \mathrm{mg} \cdot \mathrm{1}^{-1}$ of Twecn 80 (polyoxyethylcte sorbitan monooleate, Difco). For cach liter of the medium, $10 \mathrm{mg}$ of phendnthrene was dissolved in $6.7 \mathrm{ml}$ of $N, N$-dimethylformamide (DMF), autoclaved separately, and added aseptically before inoculation. The final concentration of phenanthrene was calculated to be $10 \mathrm{mg} \cdot \mathrm{l}^{-1}$, in excess of its water solubility. For experiments requiring $\left[9-{ }^{14} \mathrm{C}\right]$ phenanthrene, $0.23 \mu \mathrm{Ci} \cdot 1^{-1}$ of the radioactive compound was added with the nonradioactive phenanthrene. To isolate phenanthrene metabolites, multiple 2-1 Erlentneyer flasks containing $500 \mathrm{ml}$ of culture medium and $5 \mathrm{mg}$ of phenanthrene were incubated for $72 \mathrm{~h}$ at $28^{\circ} \mathrm{C}$ on a rotary shaker at $150 \mathrm{rpm}$.

\section{Exiraction of metabolites}

After growth of the streptomycete with phenanthrene, the spent broth was extracted with an equal volume of ethyl acetate. The ethyl acetate extract was dried, concentrated under reduced pressure at $40^{\circ} \mathrm{C}$ with a rotary evaporator (Büchi Laboratoriums- Technik, Flawil, Switzerland), and redissolved in $500 \mu \mathrm{l}$ of acetone for analysis by thin-layer chromatography or $500 \mu \mathrm{l}$ of methanol for analysis by high performance liquid chromatography.

\section{Thint-layer chromatography}

TLC was performed on $20 \times 20 \mathrm{~cm}$ glass plates coated with silica gel GF 1000 (Analtech, Inc., Newark, DE, USA). The plates were developed in a benzene:hexane $(1: 1$, vol/vol) solvent system to separate the phenanthrene metabolites from nonmetabolized phenanthrene. The metabolites were scraped off, dissolved in methanol, and filtered to remove the silica gel. After the methanol had evaporated, the metabolites were redissolved in acetone and further resolved by TLC, using a benzene: ethanol $(9: 1$, vol/vol) solvent system.

\section{High performance liquid chromatography}

Reversed-phase high performance liquid chromatography (HPLC) analyses typically were performed with a Perkin-Elmer Series 10 chromatograph (Perkin-Elmer, Inc., Norwalk, CT, USA) with a Zorbax octadecylsilane (ODS) column $(25 \mathrm{~cm} \times 4.6 \mathrm{~mm}$; Du Pont Co., Wilmington, DE, USA). The mobile phase consisted of a 40-min linear gradient of methanol : water (from 50:50, vol/vol, to 95:5) and the flow rate was maintained at $1.0 \mathrm{ml} \cdot \mathrm{min}^{-1}$ throughout. Phenanthrene metabolites eluting from the column were monitored with a Perkin-Elmer model IC-95 UV detector set at $254 \mathrm{~mm}$.

To obtain UV absorption spectra of metabolites separated by HPLC, a Hewlett-Packard model $1040 \mathrm{~A}$ diode array detector (Hewlett-Packard, Inc., Palo Alto, CA, USA) was employed. Data were collected and analyzed by a Hewlett-Packard model $300 \mathrm{com}-$ puter.

During experiments using labeled phenanthrene, fractions from the HPLC analysis of a 72-h culture grown with $\left[9-{ }^{14} \mathrm{C}\right]-$ phenanthrene were collected in scintillation vials at 30 -s intcrvals. After the addition of $7 \mathrm{ml}$ of Scintisol (Isolab, Inc., Akrom, $\mathrm{OH}$, USA) scintillation fluid, each fraction was counted for 1 min using a Packard Tri-Carb 2000CA liquid scintillation counter (Packard Instrument Co., Downers Grove. IL, USA).

\section{Mass spectrometry}

For identification of metabolites, mass spectrometry was performed by electron impact with a Finnigan MAT model 4023 quadrupole mass spectrometer (Finnigan MAT Corp., San Jose, CA, USA). Probe samples were analyed with a platinum wire direct exposure probe employing a Vacumetrics DCI current programmer (Vacumefrics Corp., Ventura, CA, USA) to generate a 0 to 3 amp current ramp over $120 \mathrm{~s}$.

Capillary column gas chromatography/mass spectrometry (GC) MS) was performed for analysis of acetylated derivatives of the melabolites. A DB $5-30 \mathrm{~N}$ bonded phase column (J \& W Scientific, Folsom, CA, USA) was employed with a head pressure of $138 \mathrm{kPa}$ of He. The column temperature was programmed to hold at $50^{\circ} \mathrm{C}$ for $1 \mathrm{~min}$ and then increase to $280^{\circ} \mathrm{C}$ at $20^{\circ} \mathrm{C}$ deg per min. Samples were injected via an OCI-3 on-column injector (Screntific Glass Engineering, Austin, TX, USA).

\section{Nuclear magnetic resonance}

${ }^{1} \mathrm{H}-\mathrm{NMR}$ spectra were obtained with a Bruker model WM 500 NMR spcelrometer (Bruker Instruments, Billerica, MA, USA). The phenanthrene dihydrodiol was dissolved in acetone- $d_{6}$ with a trace of $\mathrm{D}_{2} \mathrm{O}$ for NMR spectral measurements. Chemical shifts were recorded in parts per million (ppm) relative to tetramethylsilane (TMS).

\section{Circular dichroism}

CD spectra (Cerniglia and Yang 1984) were obtained in methanol with a Jasco model $500 \mathrm{~A}$ spectropolarimeter (Japan Spectroscopic, Tokyo, Japan). CD spectra were expressed as elliplicity for methanol solutions that read 1.0 absorbance at $264 \mathrm{~nm}$ in a UV-visible spectrophotometer with a quartz cell of $1-\mathrm{cm}$ path length. They were compared with published spectra (Miura et al. 1968; Balani et al. 1986) to determine the absolute configuration of the enantiomers.

\section{${ }^{18} \mathrm{O}_{2}$ incorporation experiments}

Cultures for experiments with ${ }^{18} \mathrm{O}_{2}$ were grow1 in 125-ml flasks conlaining $40 \mathrm{ml}$ of tryptone yeast extract broth with phenanthrene. 
The flasks were inoculated and scaled with rubber septa that had been sterilized in $70 \%$ ethanol. The atmosphere was replaced with ${ }^{18} \mathrm{O}_{2}$ as previously described (Heitkamp et al. 1988) and the cultures were incubated on a rotary shaker at $28^{\circ} \mathrm{C}$ for $72 \mathrm{~h}$.

Before and after growlh of the cultures, the retative concentrations of ${ }^{18} \mathrm{O}_{2}$ and ${ }^{16} \mathrm{O}_{2}$ in the headspaces of the flasks were determined by mass spectrometry (Heitkamp et al. 1988). Mass spectrometry for quantitation of the headspace gases was performed on a Finnigan MAT model $1015 \mathrm{D}$ quadrupole mass spectrometer with a Granville-Phillips model 203 variable leak valve (GranvillePhillips, Boulder, $\mathrm{CO}$, USA). After the leak valve had been closed by a septum and evacuated, a $0.1-\mathrm{ml}$ gas sample was injected into the inlet of the leak valve. The valve then was opened until the detection circuit of the mass spectrometer was nearly saturated.

$\Lambda$ fter growth of the cultures, the metabolites were exlracted with ethyl acetate and dried over anhydrous $\mathrm{Na}_{2} \mathrm{SO}_{4}$. The ethyl acetate was removed under reduced pressure and the residues were acetylated with acetic anhydride and pyridine (Cerniglia et al. 1989) The isotopic abundance of ${ }^{16} \mathrm{O}$ and ${ }^{18} \mathrm{O}$ species among the acetylated phenanthrene metabolites was determined by GC/MS (Heitkamp et al. 1988).

\section{Cytochrome P-450 determination}

Cytochrome $\mathrm{P}-450$ activity was demonstrated in cell extracts prepared by sonic oscillation as previously described (Sutherland et a1. 1981). After the mycelial debris had becn pelleted by centrifugation at $25,000 \times g$, the supcrnatant was centrifuged at $105,000 \times \mathrm{g}$ for $2 \mathrm{~h}$ (Stevenson ot al. 1983) and the new pellet was discarded. Protein in the extracts was determined by the method of Lowry er al. (1951), using bovine serum albumin as a standard. The reduced carbon monoxide difference spectrum was determined by the method of Omura and Sato (1964) with an Aminco DW-2 double-beam spectrophotometer (American Instrument Co., Silver Spring, MD. USA).

\section{Chemicals}

Phenanthrene and $\left[9-{ }^{14} \mathrm{C}\right]$ phenanthrene $\left(10.9 \mathrm{mCi} \cdot \mathrm{mmol}^{-1}\right)$ were obtained from Sigma Chemical Co., St. Louis, MO, USA. $N, N$ Dimethylformamide (DMF) was purchascd from Burdick and Jackson Laboratories, Muskegon, MI, USA. Ethyl acetate and methanol werc obtained from J.T. Baker Chemical Co. Phillipsburg, NJ, USA. Synthetic trans-9,10-dihydroxy-9,10-dihydrophenanthrene was preparcd from phenanthrene-9,10-quinone (Aldrich Chemical Co., Milwatuke, WI, USA) by the procedure of Harvey et al. (1975).

\section{Results}

After the growth of Streptomyces flavovirens with $\left[9{ }^{14} \mathrm{C}\right]-$ phenanthrene, the metabolites were extracted with cthyl acetate and separated by HPLC (Fig. $1 \mathrm{~A}$ ). The detectable ${ }^{14} \mathrm{C}$-containing compounds eluted at $16,2 \hat{3}, 26$, and $39 \min$ (Fig. $1 \mathrm{~B}$ ). The principal phenanthrene metabolite. which eluted at $16 \mathrm{~min}$ (Fig. $1 \mathrm{~A}$ and B), had $21.3 \%$ of the total radioactivity $(62.8 \%$ of the metabolites). The retention time and the UV absorption spectrum, which had a maximum at $270 \mathrm{~nm}$, were identical to those of synthetic phenanthrene trans-9,10-dihydrodiol. The 23-min and 26-min peaks had $6.6 \%$ and $6.0 \%$ of the radioactivity, respectively, but were not identified. Occasionally a trace of a compound eluting at $29 \mathrm{~min}$ with a retention time, UV absorption spectrum, and mass

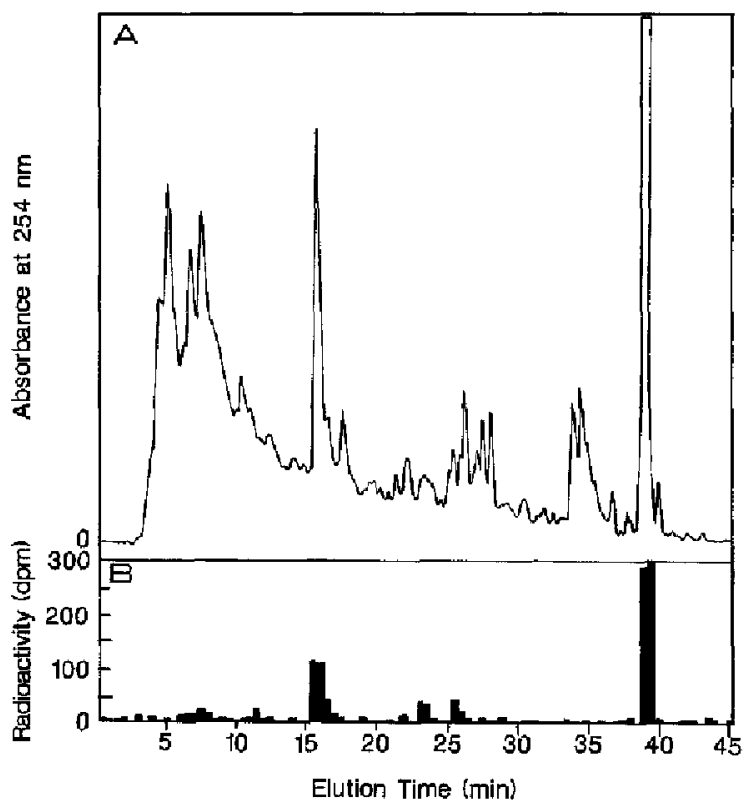

Fig. $1 \mathrm{~A}$ and B. HPLC elution profile of the metabolites produced during the growth of Streptomyces flavowirens with $\left[9-{ }^{14} \mathrm{C}\right] \mathrm{phen}-$ anthrene. (A) UV absorbance at $254 \mathrm{~mm}$ and (B) radioactivity of the fractions eluting from the HPLC column. The 16-min peak represents the principal phenanthrenc metabolitc and the $39-\mathrm{min}$ truncated peak (total height $=538 \mathrm{dpm}$ ) represents phenanthrene

spectrum similar to those of synthetic 9-phenanthrol was detected. The compound eluting at $39 \mathrm{~min}$ in Fig. 1 A and $B$ had $66.1 \%$ of the radioactivity. Its retention time and UV absorption spectrum were identical to those of phenanthrene.

The mass spectrum of the principal metabolite eluting at $16 \mathrm{~min}$ (Fig. $2 \mathrm{~A}$ ) shows a molecular ion $\left(\mathrm{M}^{+}\right)$at $\mathrm{m} / \mathrm{z}$ 212 and fragment ions at $\mathrm{m} / \mathrm{z} 194\left(\mathrm{M}^{+}-\mathrm{H}_{2} \mathrm{O}\right), 181$ $\left(\mathrm{M}^{+}-\mathrm{CH}_{2} \mathrm{OH}\right), 165\left(\mathrm{M}^{+}-\mathrm{H}_{2} \mathrm{O},-\mathrm{CHO}\right)$, and 152 $\left(\mathrm{M}^{+}-\mathrm{CH}_{2} \mathrm{OH},-\mathrm{CHO}\right)$. The mass spectrum was identical to that of synthetic phenanthrene trans-9,10-dibydrodiol.

The compound obtained by acidification of the phenanthrene 9,10-dihydrodiol metabolite had a mass spectrum (Fig. 2B) with a molecular ion $\left(\mathrm{M}^{+}\right)$at $\mathrm{m} / \mathrm{z} 194$ and a fragment ion at $\mathrm{m} / \mathrm{z} 165\left(\mathrm{M}^{+}-\mathrm{CHO}\right)$. This mass spectrum was similar to that obtained with synthetic 9-phenanthrol.

To confirm the stereochemistry of the phenanthrene 9,10-dihydrodiol metabolite produced by $S$. flavovirens, ${ }^{1} \mathrm{H}-\mathrm{NMR}$ analysis was conducted. The $500 \mathrm{MHz}{ }^{1} \mathrm{H}-$ NMR spectrum of the 9,10-dihydrodiol metabolite (acetone- $\left.\mathrm{d}_{6}\right)$ was $4.60\left(s, 2 \mathrm{H}, \mathrm{H}_{9}, \mathrm{H}_{10}\right), 7.31-7.38(m$, $\left.4 \mathrm{H}, \mathrm{H}_{2}, \mathrm{H}_{3}, \mathrm{H}_{6}, \mathrm{H}_{7}\right), 7.70\left(d, 2 \mathrm{H}, J_{1,2}=6.9 \mathrm{~Hz}, \mathrm{H}_{1}, \mathrm{H}_{8}\right)$ and $7.79\left(d, 2 \mathrm{H}, \mathrm{J}_{2,3}=6.9 \mathrm{~Hz}, \mathrm{H}_{4}, \mathrm{H}_{5}\right) \mathrm{ppm}$. The NMR spectrum of the metabolite was compared directly with that of synthetic phenanthrene trans-9,10-dihydrodiol and found to be virtually identical. Further confirmation of structure was accomplished by homonuclear decoupling experiments and nuclear Overhauser effect (NOE) difference experiments. The doublets at 7.70 and $7.79 \mathrm{ppm}\left(\mathrm{H}_{1}\right.$ and $\mathrm{H}_{4}$, respectively $)$ were irradiated independently; both experiments demonstrated that they were 


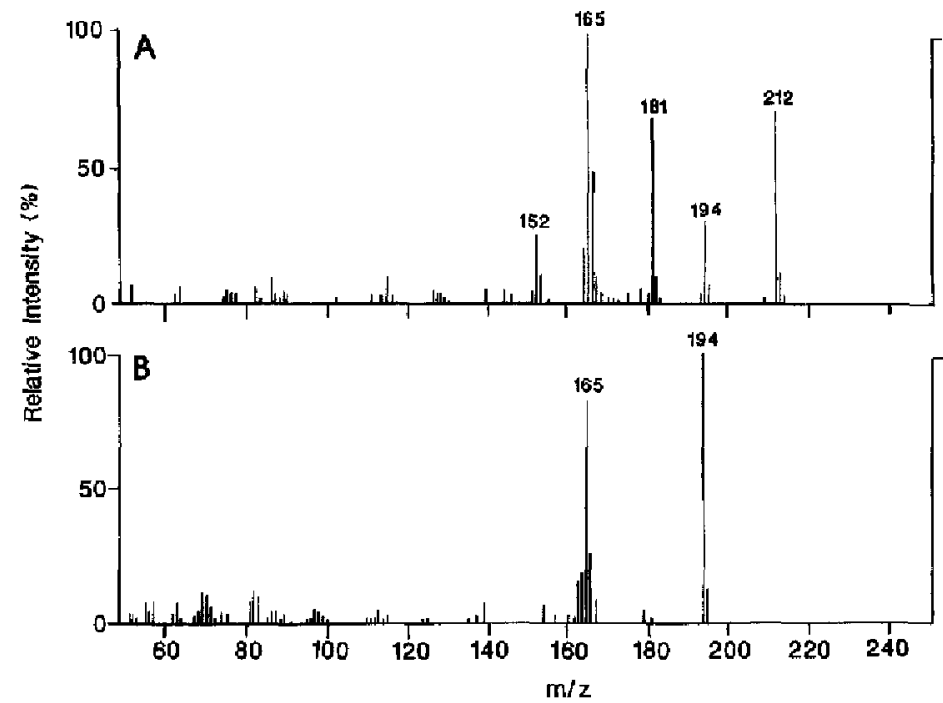

Fig. 2 A and B. Mass spectra obtained by electron impact of (A) phenanthrene trans-9,10-dihydrodiol produced from phenanthrene by $S$. flavovirens and (B) 9-phenanthrol produced by acidification of the dihydrodiol

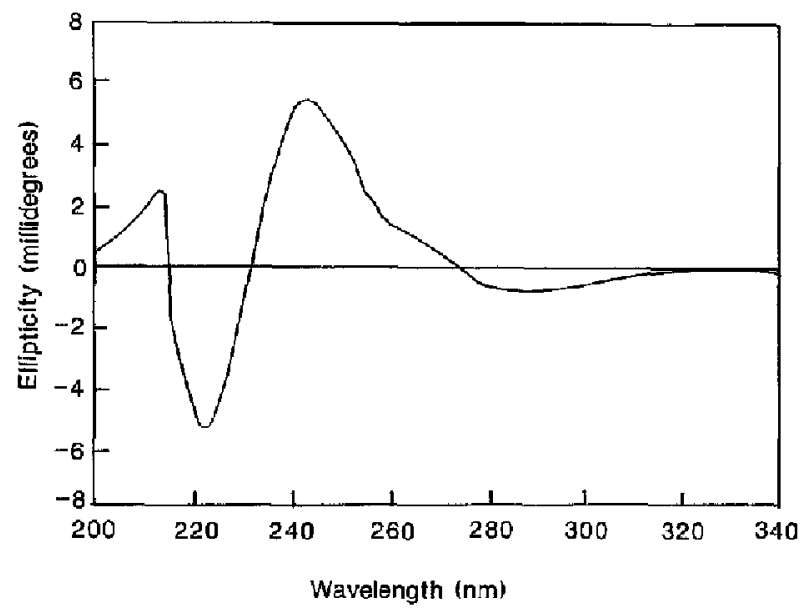

Fig. 3. Circular dichroism spectrum of the phenanthrenc trans-9,10dihydrodiol produced by S. flavovirens.

coupled to the multiplet centered about $7.35 \mathrm{ppm}$. The resonance at $4.60 \mathrm{ppm}\left(\mathrm{H}_{9}, \mathrm{H}_{10}\right)$ exhibited an NOE upon irradiation at $7.70 \mathrm{ppm}\left(\mathrm{H}_{1}, \mathrm{H}_{8}\right)$. These experimental results were consistent with the phenanthrene tranns-9,10dihydrodiol structure.

The CD spectrum of the dihydrodiol (Fig. 3) shows a negative Cotton effect at $222 \mathrm{~nm}$ and positive Cotton effects at 212 and $243 \mathrm{~nm}$. The CD spectral pattern of this melabolite was consistent with its identification as a trans rather than a cis dibydrodiol and indicated that it was the 9S,10S enantiomer (Miura et al. 1968; Balani et al. 1986).

For the experiment with ${ }^{18} \mathrm{O}_{2}$, phenanthrene trans9,10-dihydrodiols from cultures grown under atmospheres containing ${ }^{16} \mathrm{O}_{2}$ and ${ }^{18} \mathrm{O}_{2}$ were extracted, derivatized by acetylation, and subjected to GC/MS. The mass spectrum of the trans-9,10-diacetoxy-9,10-dihydrophenanthrene derived from the culture grown under air containing ${ }^{16} \mathrm{O}_{2}$ (Fig. 4 A) showed a molecular ion $\left(\mathrm{M}^{+}\right)$at $\mathrm{m} / \mathrm{z} 296$ and fragment ions at $\mathrm{m} / \mathrm{z} 236\left(\mathrm{M}^{+}-\right.$ $\left.\mathrm{CH}_{3} \mathrm{COOH}\right), 194\left(\mathrm{M}^{+}-\mathrm{CH}_{3} \mathrm{COOH},-\mathrm{CH}_{2} \mathrm{CO}\right), 178$ $\left(\mathrm{M}^{+}-\mathrm{CH}_{3} \mathrm{COOH},-\mathrm{CH}_{2} \mathrm{COO}\right)$, and $165\left(\mathrm{M}^{+}-\right.$
$\left.\mathrm{CH}_{3} \mathrm{COOH},-\mathrm{CH}_{2} \mathrm{CO},-\mathrm{CHO}\right)$. In the flasks containing ${ }^{18} \mathrm{O}_{2}$, the headspace contained 95.2 atom $\%$ of ${ }^{18} \mathrm{O}_{2}$ at the beginning before the growth of $S$.flavovirens and, due to slight leakage, 81.3 atom $\%$ of ${ }^{18} \mathrm{O}_{2}$ at the end. The mass spectrum of the trans-9,10-diacetoxy-9,10-dihydrophenanthrene derived from the culture grown under ${ }^{18} \mathrm{O}_{2}$ (Fig. 4B) shows a molecular ion $\left(\mathrm{M}^{+}\right)$at $\mathrm{m} / \mathrm{z} 298$. Fragment ions werc obtained that had $\mathrm{m} / \mathrm{z}$ of $238\left(\mathrm{M}^{+}-\right.$ $\left.\mathrm{CH}_{3} \mathrm{CO}^{16} \mathrm{OH}\right)$ and $236\left(\mathrm{M}^{+}-\mathrm{CH}_{3} \mathrm{CO}^{18} \mathrm{OH}\right) ; 196$ $\left(\mathrm{M}^{+}-\mathrm{CH}_{3} \mathrm{CO}^{16} \mathrm{OH},-\mathrm{CH}_{2} \mathrm{CO}\right)$ and $194\left(\mathrm{M}^{+}-\right.$ $\left.\mathrm{CH}_{3} \mathrm{CO}^{18} \mathrm{OH},-\mathrm{CH}_{2} \mathrm{CO}\right) ; 178\left(\mathrm{M}^{+}-\mathrm{CH}_{3} \mathrm{COOH}\right.$, $\left.-\mathrm{CH}_{2} \mathrm{COO}\right)$; and $165\left(\mathrm{M}^{+}-\mathrm{CH}_{3} \mathrm{COOH},-\mathrm{CH}_{2} \mathrm{CO}\right.$, $-\mathrm{CHO}$ ). The mass spectra in Fig. $4 \mathrm{~A}$ and $\mathrm{B}$ indicate that only one oxygen atom from ${ }^{18} \mathrm{O}_{2}$ was added to the phenanthrene molecule during formation of the dihydrodiol.

A carbon monoxide difference spectrum was obtained for the reduced $105,000 \times g$ supernatant from a cell extract of $S$. flavovirens grown with phenanthrene. The absorbance peak at $450 \mathrm{~nm}$ showed the presence of a low level (approximately $55 \mathrm{n} \boldsymbol{M}$ ) of soluble cytochrome P-450 in the extract. The carbon monoxide difference spectrum of the reduced extract from a similar culture grown without phenanthrene also had an absorbance peak at $450 \mathrm{~nm}$, indicating that phenanthrene was not required as an inducer.

\section{Discussion}

Phenanthrene can be converted to a trans-dihydrodiol by two enzymatic steps (Chaturapit and Holder 1978). The first step, catalyzed by a cytochrome P-450 monooxygenase, forms an arene oxide. The sccond step, catalyzed by an epoxide hydrolase, forms a trans-dihydrodiol. We have shown that Sircptomyces flavovirens metabolized phenanthrene at the K-region, presumably via an arene oxide, to form phenanthrene trans-9,10-dihydrodiol (Fig. 5).

The detcetion of a soluble cytochrome P-450 in $S$. flavovirens was consistent with the involvement of a cytochrome P-450 monooxygenase in the initial oxidation 


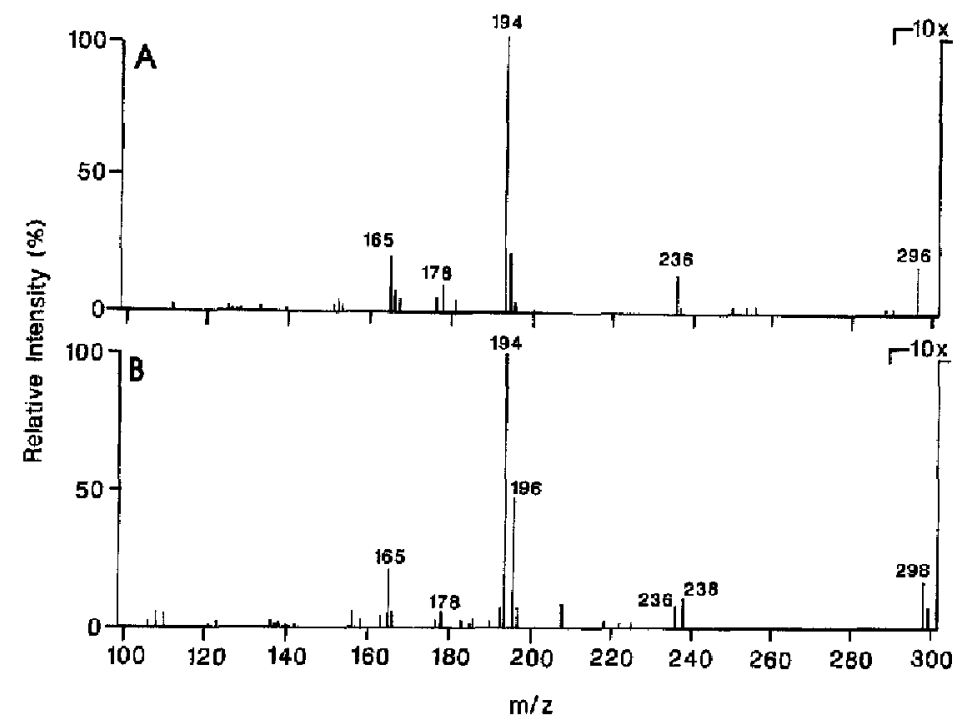

Fig. 4A and B. Mass spectra, obtained by GC/MS, of trans9,10-diacetoxy-9,10-dihydrophenanthrene produced by acetylation of the metabolites of $S$. flavorirens grown with phenanthrene (A) under ${ }^{16} \mathrm{O}_{2},(B)$ under ${ }^{18} \mathrm{O}_{2}$

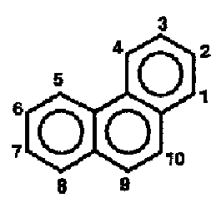

Phenanthrene
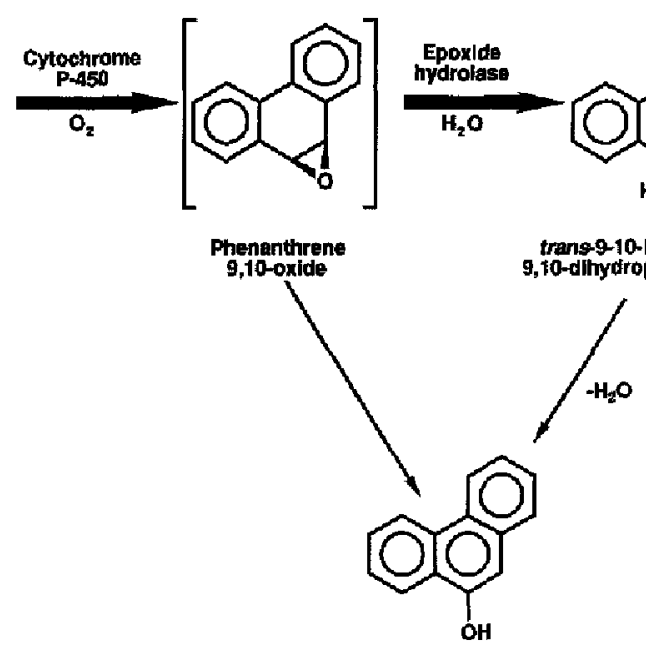

9-Phenanthro|
Fig. 5. Proposed pathway for phenanthrene metabolism in cultures inoculated with $S$. flavovirens. The bold arrows indicate the predominant pathway step. Furthermore, the mass spectrum, obtained by GC/ MS, of the acetylated derivative of the dihydrodiol produced under ${ }^{18} \mathrm{O}_{2}$ (Fig. 4) indicated that only one oxygen atom in the dihydrodiol came from $\mathrm{O}_{2}$ and the other from water.

To demonstrate that the arene oxide was an intermediate, synthetic phenanthrene 9,10-oxide was added to cultures of $S$. flavovirens that had been grown without phenanthrene. A small amount of phenanthrene trans9,10-dihydrodiol, which suggested epoxide hydrolase activity, was detected in the culture medium after $24 \mathrm{~h}$ (data not shown). Nevertheless, the nonenzymatic solvolysis of phenanthrene 9,10-oxide at $\mathrm{pH} 7$ also may produce a trans-9,10-dihydrodiol (Bruice et al. 1976).

9-Phenanthrol (Fig. 5) could be produced either by the rearrangement of the arene oxide (Bruice et al. 1976; Chaturapit and Holder 1978) or by the dehydration of the dihydrodiol (Jerina et al. 1976). Direct hydroxylation. of phenanthrene would also be theoretically possible (Tomaszewski et al. 1975).
The CD spectrum of the dihydrodiol produced by S. flavovirens was compared with that of syuthetic phenanthrene (-)-trans-9S,10S-dihydrodiol (Miura et al. 1968; Balani et a1. 1986). The comparison showed that the microbial metabolite had the (-)-9S,10S absolute configuration. In contrast, bacteria that utilize phenanthrene as a carbon source produce cis-3,4-dihydrodiols and occasionally atso cis-1,2-dihydrodiols (Jerina et a1. 1976; Cerniglia and Heitkamp 1989). Phenanthrene trans-9,10dihydrodiol, with the $95,10 S$ enantiomer in predominance, has been reported to be a metabolite of the marine cyanobacterium Agmenellum quadruplicatum (M. L. Narro, C. E. Cerniglia, D. T. Gibson, and C. Van Baalen, Abstr. Annu. Meet. Amer. Soc. Microbiol. 1984, p. 156).

A constitutive isozyme of cytochrome P-450 has been detected in S. griseolus (O'Keefe et al. 1988). Although PAHs have not been shown to induce cytochrome P-450 activity in Streptomyces spp., several other compounds induce it. Veratrole and guajacol induce cytochrome P-450 activity in S. setonii (Sutherland 1986), sulfo- 
meturon methyl and chlorimuron ethyl induce it in S. griseolus (Romesser and O'Keefe 1986; O'Keefe et al. 1988 ), and genistein induces it in S. griseus (Sariaslani and Kunz, 1986). The hydroxylation of naphthalene to 1-naphthol and of biphenyl to 2- and 4-hydroxybiphenyl has been demonstrated in extracts from genistein-induced cultures of $S$. griseus (Trower et al. 1988).

In rats and rabbits, the principal products of phenanthrene metabolism are 9S,10S-dihydrodiols (Boyland and Wolf 1950; Miura et al. 1968), although these animals also produce smaller amounts of trans-1,2-and trans-3,4dihydrodiols (Boyland and Sims 1962). Liver microsomal preparations from rats, mice, and guinea pigs generally also produce trans-9,10-dihydrodiols (Chaturapit and Holder 1978). Microsomes from guinea pigs treated with 3-methylcholanthrene, however, produce mainly trans1,2-dihydrodiols (Chaturapit and Holder 1978). The main products of phenanthrene metabolism in lobsters and sharks also are trans-9,10-dihydrodiols, although trans-1,2-dihydrodiols predominate in bony fishes (Solbakken and Palmork 1981).

The dihydrodiol produced from phenanthrene by $S$. flavovirens was similar to the principal dibydrodiol produced from phenanthrene by mammals (Miura et al. 1968; Balani et al. 1986). Since the CD spectrum indicates that the microbial metabolite had a $9 S .10 S$ absolute configuration, our results suggest that $S$. flavovirens metabolized phenanthrene in a regio- and stereospecific manner to produce a compound that is also typical of mammalian phenanthrene metabolism.

Acknowledgements. This research was supported in part by an appointmont to the ORAU Faculty Research Program at the National Conter for Toxicological Research administered by Oak Ridge Associated Universities through an interagency agreement between the U.S. Department of Energy and the U.S. Food and Drug Administration.

\section{References}

Balani SK, Van Bladeren PJ, Shirai N, Jerina DM (1986) Resolution and absolute configuration of K-region trans dihydrodiols from polycyclic aromalic hydrocarbons. J Org Chem 51:1773-1778

Black IA, Birge WJ, Westeman AG, Francis PC (1983) Comparative aquatic loxicology of aromatic hydrocarbons. Fundam Appl Toxicol 3:353 - 358

Boyland F, Sims P (1962) Metabolism of poiycyclic compounds. 21. The metabolism of phenanthrene in rabbits and rats: Dihydrodihydroxy compounds and related glucosiduronic acids. Biochen J 84:571-582

Boyland E, Wolf $G$ (1950) Metabolism of polycyclic compounds. 6. Conversion of phenanthrene into dihydroxydihydrophenanthrenes. Biochem $\mathrm{J}$ 47:64-69

Bruice PY, Bruice TC, Dansette PM, Selander HG, Yagi H, Jerina DM (1976) Comparison of the mechanisms of solvolysis and rearrangement of $\mathrm{K}$-region vs. non- $\mathrm{K}$-region arene oxides of phenanthrene. Comparative solvolytic rate constants of $\mathrm{K}$-region and non-K-region arene oxides. J Am Chem Soc 98 : 2965 2973

Bücker M, Glatt HR, Platı KL, Avnix D, Tttah Y, Blum J, Oesch F (1979) Mutagenicity of phenanthrene and phenanthrene K-region derivatives. Mutat Res $66: 337-348$

Cernigia CE (1984) Microbial metabolism of polycyclic aromatic hydrocarbons. Ady Appl Microbiol 30:31-71
Cerniglia CE, Heitkamp MA (1989) Microbial degradation of polycyclic aromatic hydrocarbons $(\mathrm{PAH})$ in the aquatic enviromment. In: Varanasi U (ed) Metabolism of polycyclic aromatic hydrocarbons in the aquatic cnvironment. CRC Press, Boca Raton, Florida, pp 41-68

Cerniglia CE, Yang SK (1984) Stercoselective metabolism of anthracene and phenanthrene by the fungus Cunninghamella elegans. Appl Environ Microbiol 47:119-124

Cerniglia CE, Campbell WL, Freman JP, Evans FE (1989) Identification of a novel metabolite in phenanthrene metabolism by the fungus Ctmminghamella elegans. Appl Environ Microbiol $55: 2275-2279$

Chaturapit S, Holder GM (1978) Studies on the hepatic microsomal metabolism of $\left[{ }^{14}\right.$ Clphenanthrene. Biochem Pharmacol 27: 1865-1871

Colla C, Fiecchi A, Treccani V (1959) Ricerche sul metabolismo ossidativo microbico dell'antracene e del fenantrene. Nota IT: Isolamento e caratterizzazione del 3,4-diidro-3,4-diossifenantrene. Ann Microhiol Enzimol 9:87-91

Crawford DL, Sutherland IB (1979) The role of actinomycetes in the decomposition of lignocellulose. Dev Ind Microbiol $20: 143-151$

Evans WC, Fernley HN, Griffiths E (1965) Oxidative metabolism of phenanthrene and anthracene by soil pseudomonads: The ring-fission mechanism. Biochem J 95:819-831

Gibson DT, Subramanian Y (1984) Microbial degradation of aromatic hydrocarbons. In: Gibson DT (ed) Microbial degradation of organic compounds. Marcel Dekker, New York, pp 181252

Grossbard E (1971) The utilization and translocation by microorganisms of carbon-14 derived from the decomposition of plant residues in soil. J Gen Microbiol 66:339-348

Guerin WF (1989) Phenanthrene degradation by estuarine surface microlayer and bulk water microbial populations. Microb Fcol $17: 89-104$

Harvey RG, Goh SH, Cortez C (1975) "K-region" oxides and related oxidized metabolites of carcinogenic aromatic hydrocarbons. J Am Chem Soc 97:3468-3479

Heitkanp MA, Cerniglia CE (1987) Effects of chemical structure and exposure on the microbial degradation of polycyclic aromatic hydrocarbons in freshwater and estuarine ecosystems. Environ Toxicol Chem 6:535-546

Heitkamp MA, Freeman JP, Miller DW, Cerniglia CE (1988) Pyrene degradation by a Mycobactorium sp.: Identification of ring oxidation and ring fission products. Appl Environ Microbiol $54: 2556-2565$

Jerina DM, Selander $\mathbf{H}$, Yagi $\mathbf{H}$, Wells MC, Davey JF, Mahadcvan V, Gibson DT (1976) Dihydrodials from anthracene and phenanthrene. J Am Chem Soc $98: 5988-5996$

Kiyohara H, Nagao K, Nomi R (1976) Degradation of phenanthrene through $o$-phthalate by an Aeromonas sp. Agric Biol Chem 40:1075-1082

Kusk KO (1981) Comparison of the effects of aromatic hydrocarbons on a taboratory alga and natural phytoplankton. Bot Mar 24:611-613

Lowry OH, Rosebrough NJ, Furr AL, Randall RJ (1951) Protein measurement with the Folin phenol reagent. $J$ Biol Chem $193: 265-275$

Mansour FA, Shady MA. (1984) Factors influencing the activity and production of nitrate reductase by certain local isolates of Streptomyces. Egypt J Bot 27:105-117

Miura R, Honmaru S, Nakazaki M (1968) The absolute configurations of the metabolites of naphthalene and phenanthrene in mammalian systcms. Tetrahedron Lett 50:5271-5274

O'Keefe DP, Romesser JA, Leto KJ (1988) Identification of constitutive and herbicide inducible cytochromes $P-450$ in Streptomyces griseolus. Arch Microbiol 149:406-412

Omura T', Sato R (1964) The carbon monoxide-binding pigment of liver microsomes. $\mathrm{f}$. Evidence for its hemoprotein nature. I Biol Chem 239:2370-2378 
Pipe RK, Moore MN (1986a) An ultrastructural study on the effects of phenanthrene on lysosomal membranes and distribution of the lysosomal enzyme- $\hat{\beta}$-glucuronidase in digestive cells of the periwinkle Littorina littorea. Aquat Toxicol 8:65-76

Pipe RK, Moore MN (1986b) Arylsulphatase activity associated with phenanthrene induced digestive cell deletion in the marine mussel Mytilus edulis. Histochem J 18:557-564

Rafii F, Crawford DI. (1988) Transfer of conjugative plasmids and mobilization of a nonconjugative plasmid between Streptomyces strains on agar and in soil. Appl Environ Microbiol 54: 1334-1340

Rogoff MH, Wender I (1957) The microbiology of coal. I. Bacterial oxidation of phenanthrene. J Bacterio1 73:264-268

Romesser JA, O'Keefe DP (1986) Induction of cytochrome P-450dependent sulfonylurea metabolism in Streptomyces griseolus. Biochen Biophys Res Commun 140:650-659

Sariaslani FS, Kunz DA (1986) Induction of cytochrome P-450 in Streptomyces griseus by soybean flour. Biochem Biophys Res Commun $141: 405-410$

Savino JF, Tanabe LL (1989) Sublethal effects of phenanthrene, nicotine, and pinane on Daphnia pulex. Bull Environ Contam Toxicol $42: 778-784$

Shiaris MP (1989) Seasonal biotransformation of naphthalene, phenanthrene, and benzo[a]pyrene in surficial estuarine sediments. Appl Environ Microbiol 55:1391-1399

Smith RV, Rosazza JP (1974) Microbial models of mammalian metabolism. Aromatic hydroxylation. Arch Biochem Biophys $161: 551-558$
Solbakken JE, Palmork KH (1981) Metabolism of phenanthrene in various marine animals. Comp Biochem Physiol 70C:21-26

Stevenson PM, Ruettinger RT, Fulco AJ (1983) Cytochrome P-450 revealed: The effect of the respiratory cytochromes on the spectrum of bacterial cytochrome P-450. Biochem Biopliys Res Commun 112:927-934

Sutherland JB (1986) Demethylation of veratrale by cytochrome P-450 in Streptomyces setomit. Appl Environ Microbiol 52:98100

Sutherland JB, Blanchette RA, Crawford DL, Pometto AL (1979) Breakdown of Douglas-ftr phloem by a lignocellulose-degrading Streptomyces. Curr Microbiol 2:123-126

Sutherland JB. Crawford DL, Pometto AL (1981) Catabolism of substituted benzoic acids by Streptomyces species. Appl Environ Microbiol 41:442-448

Taussoln WO (1928) Die Oxidation des Phenanthrens durch Bakterien. Planta 5:239-273

Tomaszewski JE, Jerina DM, Daly JW (1975) Deuterium isotope effects during formation of phenols by hepatic monooxygenases. Evidence for an alternative to the arene oxide pathway. Biochemistry 14:2024-2031

Trower MK, Sariaslani FS, Kitson FG (1988) Xenobiotic oxidation by cytochrome P-450-enriched extracts of Streptomyces griseus. Biochem Biophys Res Commun 157:1417-1422

Yoshikawa T, Ruhr L.P, Flory W, Giamalva D, Church DF, Pryor WA (1985) Toxicity of polycyclic aromatic hydrocarbons. 1. Effect of phenanthrene, pyrenc, and their ozonized products on blood chemistry in rats. Toxicol Appl Pharmacol 79:218-226 